\title{
Spinal cord stimulation in the treatment of neuropathic pain: Current perspectives of indications, cost-effectiveness, complications, and results
}

Bruno Camporeze ${ }^{1,2 *}$, Renata Faria Simm³, Iracema Araújo Estevão1, Luis Roberto Mathias Junior ${ }^{4,5}$, Paulo Henrique Pires de Aguiar ${ }^{4,5,6,7,8}$, Sylvine Carrondo-Cottin ${ }^{9}$

'League of Neurosurgery of Medical School of Sao Francisco University, Bragança Paulista, São Paulo, Brazil, ${ }^{2}$ Scientific initiation scholarship program, Institute of Medical Assistance of the State Public Servant (IAMSPE), São Paulo, Brazil, ${ }^{3}$ Division of Neurology of Santa Paula Hospital, São Paulo, Brazil, ${ }^{4}$ Division of Neurosurgery of Santa Paula Hospital, São Paulo, Brazil, ${ }^{5}$ Division of Neurosurgery of Oswaldo Cruz Hospital, São Paulo, Brazil, ${ }^{6}$ Department of Surgery, Post Graduation Section in Surgery Program of Federal University Rio Grande do Sul, Porto Alegre-RS, Brazil, 'Department of Neurology of Pontifical Catholic University of São Paulo, Sorocaba, São Paulo, Brazil, ${ }^{8}$ Department of Neurosurgery, Public Servant Hospital of São Paulo, São Paulo, Brazil, ${ }^{9} \mathrm{CHU}$ de Québec Research Center (Enfant-Jésus Hospital), Department of Neurosciences of Faculty of Medicine, Laval University, Quebec, Canada

\section{ABSTRACT}

Introduction: The spinal cord stimulation (SCS) has been described as a valuable neuromodulating procedure in the management of chronic and medically untreated neuropathic pain. Although many studies have discussed the use of this technique, a question still remains regarding its efficacy in different medical conditions with different etiology in the long term. The aim of this paper is to discuss the risks, complications, cost-effectiveness, and results of SCS in patients affected by chronic neuropathic pain based on the comprehensive literature review.

Methods: Bibliographic search of references from 1950 to 2016 using the databases MEDLINE, LILACS, SciELO, PubMed, and applied language as selection criteria, choosing preferably recent articles written in Portuguese, Spanish, or English.

Results: Based on literature review, SCS is a safe, reversible, adjustable, and non-destructive surgical procedure demonstrating a significant effect in the reduction of pain intensity and improvement in the quality of life in these patients. Furthermore, in spite of the initial high cost to its application, SCS has been associated with lower rates of complications and high rates of cost-effectiveness when compared to standard therapies.

Conclusion: Although used in medical conditions with different etiology, the procedure is still an effective and a cost-effective approach to neuropathic pain, mainly in patients affected by Failed Back Surgery Syndrome (FBSS) and complex regional pain syndrome.

Key words: Spinal cord stimulation; neuropathic pain; pain management; neurosurgical procedure; electric stimulation therapy *Corresponding author: Bruno Camporeze, Boa Esperança Street
184 Vitel, 03408-000, São Paulo, Brazil.

Phone: +55-11-97312-9070, E-mail: bruno4971202@hotmail.com

Submitted: 4 January 2017/Accepted: 3 April 2017

\section{INTRODUCTION}

Pain is defined as an unpleasant sensation and emotional experience related to actual or potential tissue damage. It may be divided into nociceptive, caused by activation of pain receptors related to 
tissue damage, or neuropathic pain, caused by a primary lesion or dysfunction in the central, peripheral, or both nervous systems (1-5).

Recent studies have reported a significant increase in the number of patients affected by refractory neuropathic pain. The actual prevalence of neuropathic pain in general population has been estimated from $6.9 \%$ to $8 \%$. About $74 \%$ of neuropathic pain cases present with moderate-to-severe intensity. Neuropathic pain comprises more than $17 \%$ of patients' pain complaint $(3,4,6-12)$.

Management of neuropathic pain is a challenge often associated with high rates of disappointment. Usually, neuropathic pain is managed by the multidisciplinary team and includes pharmacological treatment by opioids, anticonvulsants, tricyclic antidepressants, and corticosteroids. In a few scenarios, non-steroidal anti-inflammatory drugs are used. Furthermore, occupational therapies can be conducted $(1,4,9,10)$.

The surgical management of neuropathic pain includes ablative and non-ablative neurosurgical approaches. These include rhizotomy, sympathectomy, cordotomy, hypophysectomy, regional infusion of sympatholytic infiltrations, and intrathecal administration of drugs. Recently, electrical stimulation therapies such as spinal cord stimulation (SCS), motor cortex stimulation, and deep brain stimulation have been described (13-23).

SCS, also known as dorsal column stimulation $(24,25)$, is a reversible, adjustable, and non-destructive surgical approach. Painful symptoms are controlled through the spinal electrical stimulation, using epidural electrode placed in the posterior horn of the spinal cord $(13,15,16,22,26-28)$.

SCS was firstly described by Shealy et al. (29), in 1967 , as an alternative for ablative neurosurgical procedures in the management of refractory pain. Since then, it has been estimated that more than 12,000 SCS systems are sold annually worldwide. SCS has shown significant results in the treatment of a wide range of pain disorders (27).

Our aim is to clarify the indications, risks, complications, and prognosis of patients treated with SCS for neuropathic pain. We will discuss the efficacy of SCS in the control of pain and cost-effectiveness of the procedure.

\section{METHODS}

We searched MEDLINE, LILACS, SciELO, and PubMed databases using "neuropathic pain" and "SCS" keywords. We included articles published between 1950 and 2016, written in Portuguese, Spanish, or English language and involving only human subjects. Only the relevant studies were selected for this review (Figure 1).

\section{Physiological mechanisms of SCS}

SCS mechanism is complex and involves more than just one model or mechanism. SCS is associated with sequentials or simultaneous interactions of multiple physiological mechanisms of pain conduction (30-36). The classical mechanism of pain was described in 1965 by Melzack and Wall (36). Recently, the effect of SCS on blood flow and the somatosensory system had been described (Figure 2) (16,30-33).

In 2000, Kemler et al. (32) described the possible relationship between SCS and changes in microcirculation blood flow in patients $(n=36)$ affected by unilateral complex regional pain syndrome (CRPS). The study showed that $66.7 \%(n=24)$ of the patients were responsive in the stimulation test with the SCS system. The total of $91.7 \%$ of these patients $(n=$ $22 / 24)$, whose pain was located in the hand $(58 \%)$ and in the foot $(33.4 \%)$, had undergone the previous unsuccessful sympathectomy. The authors concluded that patients with lower vasoconstriction rates had a significant pain improvement $(p<0.01)$ when compared to control patients. This has indicated a decrease in sympathetic tone and an increase in vasodilation during the use of the SCS system. Nevertheless, SCS did not result in any microcirculatory changes as there was no difference when compared to baseline values of patients or the contralateral, clinically unaffected side.

In 2016, Deogaonkar et al. (31) presented the results of the functional magnetic resonance imaging in patients $(n=10)$ affected by CRPS in the lower limbs, who had previously undergone SCS. The results of this study showed significant differences $(p<0.05)$ in resting-state connectivity between SCS off and optimal state in several regions related to pain perception. The regions included the left frontal insula, right primary and secondary somatosensory cortices, as well 
Potential relevant essays identified throngh the keywords in PubMed, IILACS, SciEIO, MEDLINE from 1950 to 2016 ( $n=1405$ )

- Essays exchuded becanse of obvions irrelevance after reading the titles and abstracts $(n=402)$

-Essays excluded due to inability to access the finl text, and applyelsewhere $(n=157)$

-Essays excluded becanse the population was not $\operatorname{human}(\mathrm{n}=705)$

- Clinical triak exchaded becamse of not providing sufficient data for clinical ontcome or low level of evidence $(n=34)$

-Reviews excluded ( $\mathrm{n}=50$ )

-Essays included becanse significant phisiological social, definitions, descriptions and others significant datasabout thenearhophatic pain* $(n=15)$

Potencial relevantessays included for fnther review in fnll text $(n=141)$

Essays included in the article $(n=72)$

*inchudinggnidelines, meta-analysis, systematic reviews, reviews

FIGURE 1. Articles were searched in several databases, using the keywords "neuropathic pain" and "spinal cord stimulation." After applying the relevance, completeness and quality criteria, 72 out of 1405 identified articles were selected.

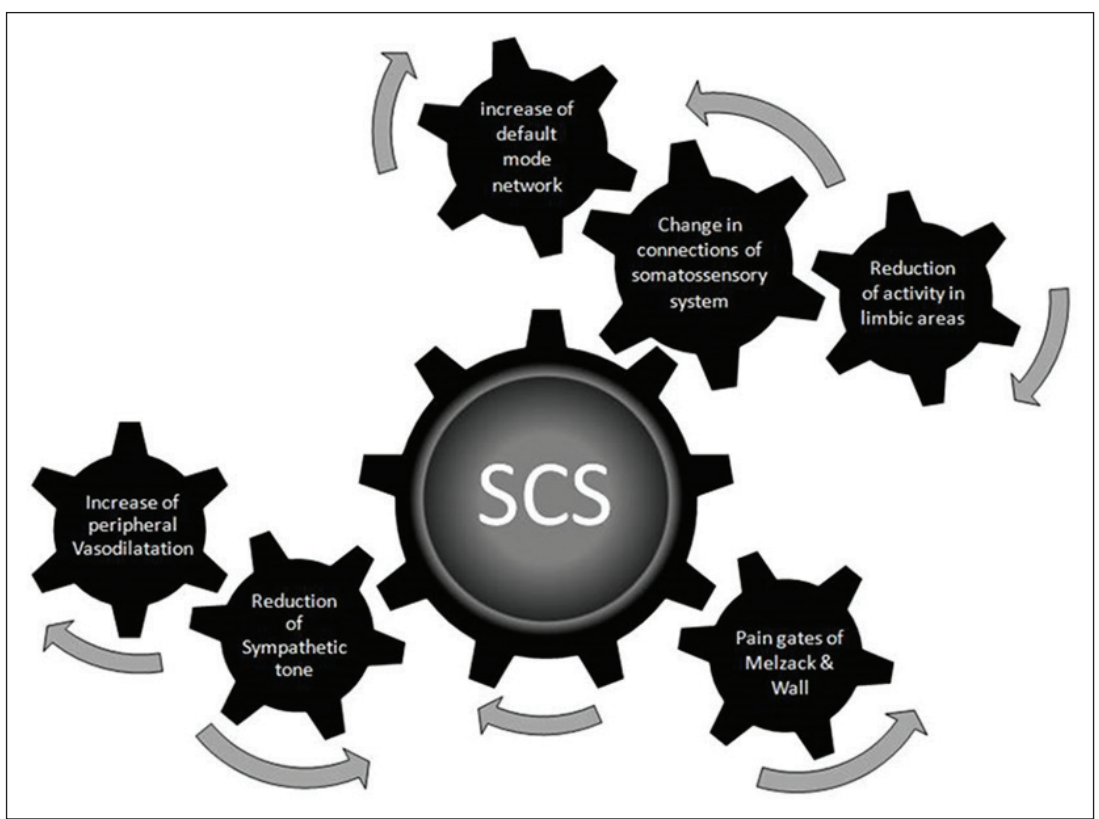

FIGURE 2. Physiological mechanisms of spinal cord stimulation (SCS) include more than just one model or mechanism, illustrating the association between the classical mechanism of pain described by Melzack and Wall (36) and the effect of SCS on blood flow and the somatosensory system (16,30-33). 


\begin{tabular}{ll}
\hline TABLE 1. Key points of the patient selection criteria \\
\hline Medically intractable pain & $\begin{array}{l}\text { Failure of other surgical } \\
\text { procedures of pain control }\end{array}$ \\
$\begin{array}{l}\text { Pain reduction higher } \\
\text { than } 50 \% \text { in trial }\end{array}$ & $\begin{array}{l}\text { Absence of malignant } \\
\text { neoplasms, psychiatric disorders, } \\
\text { stimulation }\end{array}$ \\
& $\begin{array}{l}\text { or other treatable organic or } \\
\text { functional etiology }\end{array}$ \\
\hline
\end{tabular}

as in regions involved in the default mode network $(\mathrm{DMN})$, such as the precuneus. In addition, these changes in the connectivity across the entire brain during the optimal SCS were found to result in pain relief. Furthermore, the results indicated the increased connection strength between the somatosensory and DMN, and the decreased connection strength between somatosensory and limbic areas. The authors suggested that pain relief from SCS may be reducing a negative emotional processing associated with pain, allowing somatosensory areas to become more integrated into the default mode activity.

In 2012, Moens et al. (37) showed similar results to those discussed by Deogaonkar et al. (31) in patients $(n=20)$ affected by failed back surgery syndrome (FBSS). The authors investigated the deactivation of the bilateral medial thalamus and its connections to the rostral and caudal cingulate cortex and the insula. The study also showed immediate pain relief obtained by short-term SCS correlated negatively with activity in the inferior olivary nucleus, the cerebellum, and the rostral anterior cingulate cortex.

\section{Selection of patients}

The adequate selection of the patients directly affects the success of the SCS approach. During the selection, different factors have been considered, such as the etiology of pain, type and localization of pain, age of the patient, and the radiological and neurological findings summarized in Table 1 (20-22,28,30,31,37-44).

Patients considered for SCS procedure are required to comply with the following criteria:

- Patients with medical intractability of neuropathic pain $(20,22,26,32,38,45-49)$;

- Patients that reported the reduction of $50 \%$ or more in pain intensity in the trial simulation (3-15 days) by percutaneous implantation when compared with the baseline (20-22,26,32,38,45-49);

- Patients diagnosed with complex regional pain syndrome (CRPS), Type I - A level of evidence (20-22,27,28,30,38-43);

- Absence of the major psychiatric disorder including somatization disorder complaints (20-22,38);

- Patients with unsuccessful control of neuropathic pain after the repeated functional or ablative surgical procedure for pain treatment $(20-22,38,45)$;

- Patients with pain not associated with malignancy (38).

During the surgical procedure of trial implantation, patients should be asked to indicate the location of parenthesis (change of sensibility correlated to the spinal segment stimulated) since it is relevant to confirm that the resultant parenthesis overlaps with the painful area to achieve good analgesia $(20-22,26,28,45)$.

\section{RESULTS IN PAIN MANAGEMENT}

It is essential to determine the cause of pain to effectively manage it. In terms of the neuropathic pain etiology, SCS has been applied in the treatment of deafferentation pain, central pain, phantom limb pain (PLP), causalgia, myelopathy, oncologic pain, lumbosacral fibrosis, postherpetic neuralgia (PHN), FBSS, CRPS, reflex sympathetic dystrophy (RSD), spinal cord, brainstem or brain injury, and others $\quad(3,13-15,22,32,33,38,42,43,46-49,50-57)$. Since there are many different types of neuropathic pain, there is no reason to believe that one procedure will be effective in the treatment of all conditions.

In 2006, Lee and Pilitsis (38) reported that SCS is an effective treatment for pain associated with FBSS, refractory angina pectoris, peripheral vascular disease, and CRPS Type I. Between $60 \%$ and $80 \%$ of patients with FBSS, peripheral vascular disease and CRPS Type I had a significant improvement in the quality of life related to returning to daily activities. The SCS procedure in patients affected by refractory angina pectoris resulted in a significant decrease in hospital admissions and chest pain, as well as an increased exercise duration. In addition, the comparison between SCS and open surgical procedures showed that SCS demonstrated less morbidity rates 
and similar or higher rates of pain control and improvement in the quality of life.

In 2008, Olsson et al. (50) presented the results of SCS in children ( $n=7 ; 100 \%$ girls) diagnosed with CRPS Type I, within the mean age $13 \pm 1.1$ years (ranging from 11 to 14 years). Regarding the location of the pain, this paper showed in feet $(57.1 \%$ of cases; $n=4)$, hands $(14.3 \% ; n=1)$, unilateral knee $(14.3 \% ; n=1)$, and bilateral knees $(14.3 \% ; n=1)$. Complications were reported in $14.3 \%(n=1)$ of patients affected by subcutaneous infection, which resulted in the surgical removal of the SCS system. All the patients were treated with sympathetic blocks (SB), without a therapeutic effect. However, the SCS procedure had a pain relieving effect after 1 or 2 weeks of trial stimulation. The pain alleviation was complete in $71 \%(n=5)$ of the patients, ranging from 1 to 8 years after the intervention, after another 2-6 weeks.

In their article in 2008, Kemler et al. (47) described the SCS results in patients diagnosed with CRPS Type I $(n=36)$, whose follow-up lasted 5 years. The authors demonstrated an effective long-term pain treatment for $63 \%(n=24)$ of the implanted patients. The total of $100 \%(n=36)$ and $53 \%(n$ $=19$ ) of these patients presented more than $50 \%$ of pain reduction and more than $80 \%$ of pain intensity by the visual analog scale in the first post-operative year, respectively. The percentage of patients who reported at least $30 \%$ reduction in pain with SCS was reduced from $100 \%$ to $41 \%$ in the fifth post-operative year. During the 5-year treatment, 29 technical complications were reported, including lead migration, pulse generator replacement, explanation, and reimplantation of the system. About $72 \%(n=21)$ of the complications took place in the $1^{\text {st }} 2$ years, while the annual complication rate in the remaining 3 years was 5\%. Geurts et al. (48), Williams et al. (55), Harke et al. (56), Kumar et al. (58), Kemler and Furnée (46), Kemler et al. $(47,49)$, and Van-Eijs et al. (54) reported similar results on pain management.

In 2012, Van-Eijs et al. (54) described the results of the comparison between the standard therapy and the use of SCS in patients $(n=61)$ affected by CRPS. The standard therapy included physical therapy (PT), topical dimethyl sulfoxide, analgesics, transcutaneous stimulation, and sympathetic blockade. In these patients, $90.1 \%(n=55)$ were treated with the standard therapy and $9.9 \%(n=6)$ were included for the SCS treatment. The overall mean pain relief after 1 year was 35\% and the mental component improved in both groups, while none of the SCS-treated patients showed a clear improvement in the functional outcome. No significant difference of effect on the physical component was demonstrated as well.

In their 2016 study, Kim et al. (14) presented the results of the continuous thoracic sympathetic ganglion block associated with SCS in patients $(n=3)$ diagnosed with unilateral CRPS in their upper limbs. The mean age of patients was 53.6 years, ranging from 49 to 56 years. The authors concluded that the thoracic SB was efficient in the treatment of neuropathic pain of upper extremities once the approach was associated with improvement higher than $50 \%$ of basal pain. Nevertheless, this procedure often had temporary effects. Although the authors indicated that SCS did not achieve the total control of pain, this approach avoided several complications taking place in the continuous SB.

In 2011, Sears et al. (42) described the results of SCS in patients $(n=35)$ diagnosed with CRPS $(n=18)$ and FBSS $(n=17)$. A total of 18 male and 17 female patients participated in the CRPS and FBSS groups,



FIGURE 3. A patient affected by chronic phantom-limb pain was implanted with a cervical medullary electrode. The intraoperative radiography shows the positioning of the adequate electrode in the middle of vertebral column, inside the epidural. 


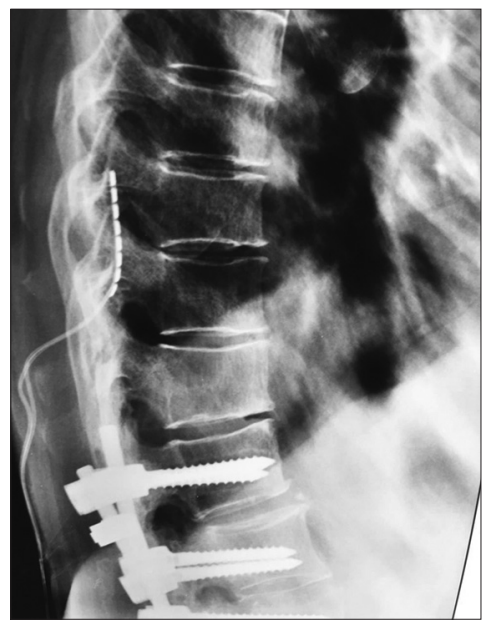

FIGURE 4. A patient diagnosed with chronic FBSS after lumbar arthrodesis underwent spinal cord stimulation implantation. The intraoperative radiography, in the sagittal plane, shows the positioning of the adequate electrode in the middle of vertebral column, inside the epidural.

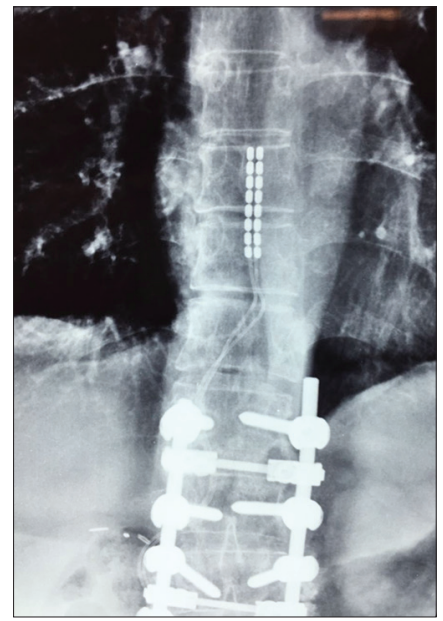

FIGURE 5. A patient affected by chronic FBSS after lumbar arthrodesis underwent SCS system implantation. The intraoperative radiography, in the sagittal plane, shows the positioning of the adequate electrode in the middle of the vertebral column, inside the epidural.

respectively. The mean age was 44.3 years and 51.6 years, the duration of pain at the time of the surgery was 9.6 years and 8.5 years, and the duration of a follow-up after the surgery was 5.0 years and 3.8 years in CRPS and FBSS groups, respectively. More than $50 \%$ of the patients with CRPS reported more than $50 \%$ pain relief at a mean follow-up of
4.4 years, while $30 \%$ of the FBSS patients reported a $50 \%$ or greater improvement at a mean follow-up of 3.8 years. The review reported more than $50 \%$ pain relief in $55.6 \%$ of CRPS patients $(p<0.01)$ and $30 \%$ of FBSS patients $(p<0.01)$. Furthermore, $77.8 \%$ of CRPS patients $(p=0.15)$ and $70.6 \%$ of FBSS patients $(p=0.01)$ indicated that they would undergo a SCS surgery again for the same outcome. In this respect, Cruccu et al. (13), Kumar et al. (41), Taylor et al. (40), Cameron (27), North et al. (59), and Kumar et al. (60) reported similar results on pain management obtained by conducting SCS in patients affected by FBSS.

Simpson et al. (52) in 2009 and Wills et al. (61) in 2015 provided the results of the systematic review on the clinical effects of SCS in patients affected by neuropathic and ischemic pain. Their studies were based on more than 600 quotes identified from 13 databases from 1950 to 2014 . The authors showed in this study that the presence of clinical benefits for refractory angina is showed in a short-term treatment. Furthermore, this also applies to the improvement of the quality of life, enhancement of physical performance, reduction in the use of nitroglycerine, decrease in hospitalization admissions, and reduction in pain intensity and frequency in these patients. With this regard, in 1999, Vaarwerk et al. (62) presented the results of the SCS use in patients $(n=517)$ diagnosed with refractory angina pectoris. The study included $71 \%$ male patients $(n=367)$, a median follow-up was 23 months (ranging from 0 to 128$)$, within the mean age $63.9 \pm 10.1$ years. Therefore, this study and other authors, such as Murphy and Giles (24) demonstrated the improvement ranging from 3.5 to $2.1(p<0.01)$, based on the New York Heart Association Functional Classification. In addition to the improvement, the total percentage of hospital admissions was reduced to $30 \%(p<0.001)$.

Numerous literary sources report variable success rates in the neuropathic pain management with SCS in patients affected by the section of the spinal cord conus and cauda equina, complete transverse section of the spinal cord, injury in multiple radicular roots, and PLP as shown in Figure $3(5,13,21,22,63,64)$. Patients diagnosed with CRPS, FBSS (Figures 4 and 5), and PHN have shown significant success rates in pain management 
TABLE 2. Pain control rates of SCS

\begin{tabular}{|c|c|c|c|c|c|c|}
\hline Authors & Year & $n$ & Etiology & $\begin{array}{l}\text { Complete pain } \\
\text { relief with SCS }\end{array}$ & $\begin{array}{l}\text { Mean pain relief higher than } \\
50 \% \text { of baseline }\end{array}$ & Mean follow-up \\
\hline Olsson et al. (50) & 2008 & 7 & CRPS & $71 \%$ of patients & $100 \%$ of patients & 8 years \\
\hline Kemler et al. (47) & 2008 & 36 & CRPS & $63 \%$ of patients & $83 \%$ of patients & 5 years \\
\hline Van-Eijs et al. (54) & 2012 & 61 & CRPS & $0 \%$ of patients & $0 \%$ of patients & 1 year \\
\hline Kim et al. (14) & 2016 & 3 & CRPS & $0 \%$ of patients & $100 \%$ of patients & 1 year \\
\hline Sears et al. (42) & 2011 & 35 & $\begin{array}{l}\text { FBSS }(n=17) \\
\text { CRPS }(n=18)\end{array}$ & $\begin{array}{l}0 \% \text { of patients } \\
0 \% \text { of patients }\end{array}$ & $\begin{array}{l}>50 \% \text { of patients }>50 \% \text { of } \\
\text { patients }\end{array}$ & 4 years 5 years \\
\hline Harke et al. (56) & 2002 & 28 & $\mathrm{PHN}$ & $0 \%$ of patients & $82 \%$ of patients & 3 years \\
\hline Kumar et al. (60) & 2002 & 104 & FBSS & $0 \%$ of patients & $88 \%$ of patients & 5 years \\
\hline Williams et al. (55) & 2009 & 1 & CRPS & $100 \%$ of patients & $100 \%$ of patients & 1 year \\
\hline Geurts et al. (48) & 2012 & 84 & CRPS & $0 \%$ of patients & $64 \%$ of patients & 11 years \\
\hline Viswanathan et al., (41) & 2010 & 4 & PLP & $25 \%$ of patients & $100 \%$ of patients & 1 year \\
\hline
\end{tabular}

${ }^{*} n$ : Number of patients; PHN: Postherpetic neuralgia; CRPS: Complex regional pain syndrome; FBSS: Failed back pain syndrome;

PLP: Phantom limb pain. SCS: Spinal cord stimulation

TABLE 3. Long-term complications rates of SCS

\begin{tabular}{lcc}
\hline Complication & $\begin{array}{c}\text { Incidence } \\
\text { rates (\%) }\end{array}$ & $n$ (510 patients) $^{*}$ \\
\hline Absence of complications & 59 & 301 \\
Lead migration & 17.4 & 89 \\
Hardware malfunction & 7.5 & 38 \\
Lead breakage & 4.9 & 25 \\
Hematomas & 3.5 & 18 \\
Infection & 2.8 & 14 \\
Discomfort at the pulse & 1 & 5 \\
generator & & \\
Cerebral fluid leak & 1 & 5 \\
Aseptic meningitis & 0.8 & 4 \\
Muscle spasms & 0.6 & 3 \\
Rotation of the pulse & 0.6 & 3 \\
generator & & \\
Rejection of the system & 0.4 & 2 \\
Headache, asthenia, & 0.4 & 2 \\
dizziness & & \\
Paralysis & 0.1 & 1 \\
\hline
\end{tabular}

*Franzini et al. (69) and Meglio et al. (66). SCS: Spinal cord stimulation

and cost-effectiveness associated with low rates of complications. The total pain management was rarely obtained by the use of SCS as therapy as indicated in Tables 2-4 (22,38,39,41,50,58,60,65-67).

\section{Complications}

Although long-term complications rates of SCS can vary in this type of surgical procedure, such as the

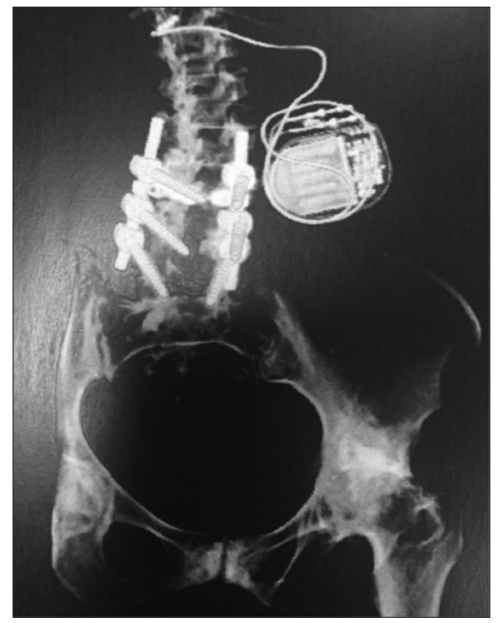

FIGURE 6. A patient diagnosed with chronic FBSS after lumbar arthrodesis underwent spinal cord stimulation implantation. The intraoperative radiography, at the coronal section, shows the displacement of the implanted electrode.

presence of electrode migration (Figure 6), battery or pulse generator failures, hardware malfunction, also, the paresthesia in other body parts, and superficial infections were associated to SCS approach. Furthermore, the low rates of electrode breakage, change of amplitude of pulse by bodily movements, unwanted stimulation, unsatisfactory positioning of the electrode or generator, urinary disturbances, cerebrospinal fluid leakage, subcutaneous hematomas, epidural hematomas, deep infections, aseptic meningitis, paralysis, spinal cord injury, headache, 
TABLE 4. Cost-effectiveness of main neuropathic pain therapies

\begin{tabular}{lclll}
\hline Authors & Number of patients & Etiology & Treatment & Mean treatment cost \\
\hline Kemler and Furnée (46) & 18 & CRPS & SCS+PT & EUR 171,153.00 (in 1 year of follow-up) \\
Kemler and Furnée (46) & 36 & CRPS & PT & EUR 229,624.00 (in 1 year of follow-up) \\
Kemler and Furnée. (46) & 24 & CRPS & SCS & EUR 193,580.00 (in 1 year of follow-up) \\
Manca et al. (57) & 50 & FBSS & SCS+CPT & EUR 12,653 (in 0.5 year of follow-up) \\
Manca et al. (57) & 50 & FBSS & CPT & EUR 2,594 (in 0.5 year of follow-up) \\
Manca et al. (57) & 50 & FBSS & SCS+CPT & EUR 1,692 (in 1 year of follow-up) \\
Manca et al. (57) & 50 & FBSS & CPT & EUR 2,664 (in 1 year of follow-up) \\
Kumar et al. (41) & 52 & FBSS & CPT & USD 38,029.00 (in 5 years of follow-up) \\
Kumar et al. (41) & 52 & FBSS & SCS & USD 29,123.00 (in 5 years of follow-up) \\
\hline
\end{tabular}

*SCS: Spinal cord stimulation; CPT: Conventional pharmacological treatment; PT: Physical therapy; CRPS: Complex regional pain syndrome; FBSS: Failed back surgery syndrome

asthenia, dizziness, muscle spasms, and pain located at the incision, electrode, or receiver site are risks to be considered during and after the surgical act $(13,27,32,38-40,46-49,68)$.

In 2004, Cameron (27) summarized the 20-year application of SCS, including the data obtained from 51 research papers, comprising 2972 patients in total. This study specified complications related to technical or biological plots. The most common technical complications are battery or pulse generator failuresand electrode breakage and dislocation (27). The most frequently reported biological complications are cerebrospinal fluid (CSF) leakage, infections, and pain located at the incision, electrode, and receiver site (27). It is important to underline that this study identified paralysis and electrode migration as the most serious and the most common SCS complication, respectively. In addition, this assessment showed that the majority of complications were not considered as life-threatening and could be mainly solved by removing the device.

In 2005, Franzini et al. (69) presented the results of a retrospective analysis of a 22 -year experience in 410 patients who underwent the SCS implantation. The authors reported displaced electrode, fractured electrode, other hardware malfunctions, subcutaneous hematomas, infection, CSF leakage, rotation of the pulse generator, and discomfort at the pulse generator site in $21.5 \%(n=89), 5.9 \%(n=25)$, $8.1 \%(n=34), 4.4 \%(n=18), 3.4 \%(n=14), 0.5 \%$ $(n=2), 0.7 \%(n=3)$, and $1.2 \%(n=5)$ patients, respectively.
In their study in 1989, Meglio et al. (66) presented the results of the use of SCS in a case series $(n=100)$ of patients. The examined patients were affected by obstructive peripheral vasculopathy $(n=40)$, previous herpes zoster infection $(n=10)$, incomplete traumatic spinal cord lesion $(n=15)$, root and/or nerve damage $(n=9)$, cancer $(n=11)$, earlier back surgery $(n=19)$, and undetermined pain etiology $(n=5)$. This study reported complications related to aseptic meningitis, infection, paralysis (paraplegia), rejection of the electrode leads, CSF leakage, and the system failure in $4 \%(n=4), 4 \%(n=4), 1 \%$ $(n=1), 2 \%(n=2), 3 \%(n=3)$, and $4 \%(n=4)$, respectively. In this respect, all the cases of meningitis were treated with no permanent damage. Side effects, such as headache, asthenia, and dizziness were identified in $2 \%(n=2)$ of the patients. About $3 \%(n=3)$ of the patients presented muscle twitching due to the radicular stimulation and $1 \%(n=1)$ reported signs of muscular contraction caused by the activation of the pyramidal tracts. In terms of pain improvement, no clinical benefits of SCS in cancer pain or in central deafferentation pain were identified. Significant results were reported for vasculopathic pain and PHN. Similar results were also found by Meglio et al. (67) and Cioni et al. (65).

The authors reported high rates of patients with the absence of complications (more than $50 \%$ of patients) and the presence of lead migration (17\% of patients) as the main complication of SCS procedure. The technical complications affected more than $30 \%$ of patients and represented the most common complication of this procedure. Paralysis indicated the lower incidence 
rate $(<0.1 \%)$ and the most severe complication of this procedure. Furthermore, SCS has reported low rates of system rejection ( $<2 \%$ of cases).

Benefits of the neuropathic pain treatment by the SCS system include short hospitalization time, high rates of pain reduction following the procedure related to the reduction of pharmacological treatment costs, low rates of long-term complications, and the resources optimization. These factors, in addition to an increase in the life expectancy of the inhabitants of emerging countries, indicate the need for more clinical studies on this procedure.

\section{Cost-effectiveness}

In 2006, Taylor et al. (39) presented the results of the systematic review and the meta-analysis of the clinical SCS cost-effectiveness in the management of CRPS patients. This study comprised 25 case series, 1 randomized controlled trial and 1 cost-effectiveness study. During the median follow-up period of 33 months, patients affected by CRPS Type I or Type II presented a significant pain relief higher than $50 \%$ in intensity in $67 \%$ of patients implanted with SCS system. The economic analysis based on the randomized controlled trial indicated a lifetime cost-saving of approximately $€ 58,470$ (US \$60,800) using SCS plus PT compared to PT. The mean cost per quality-adjusted life-year at a follow-up period of 12 months amounted to $€ 22,580$ (US \$23,480). SCS has been proven a cost-effective and an efficient treatment of CRPS Type I (A level evidence), while Type II presented D level evidence with regard to cost-effectiveness.

In 2002, Kemler and Furnée (46) described the results of a cost-effectiveness analysis on the use of SCS in patients affected by chronic RSD $(n=54)$ in the $1^{\text {st }}$ year of the post-operative follow-up. This study demonstrated that the SCS costs were mainly related to the implantation costs $(€ 202,986)$, while the remaining costs were generated by test stimulation $(€ 30,128)$ and complications $(€ 11,904)$. Therefore, the authors concluded that the mean cost per patient for SCS procedure achieving significant results was $€ 193,580$. SCS associated with PT and medical pain management was estimated to $€ 171,153$ and $€ 229,624$, respectively.

In their study in 2008, Kemler et al. (47) presented the results of a cost-effectiveness analysis on the use of SCS in patients affected by chronic RSD $(n=54)$ in the $5^{\text {th }}$ year of the post-operative follow-up. It has also been concluded that SCS would be less expensive than alternative therapies after 3 years of the successful treatment, and in 2 years, it would be cost-effective for another period of 2-3 years. The study reported $99 \%(n=52)$ of the patients who affirmed to repeat the treatment, if necessary, for the same outcome. Similar results were found by Turner et al. (53), Hollingworth et al. (70), Dario et al. (71), and Ohnmeiss et al. (72) in their studies on pain management of FBSS, and Simpson et al. (52) in their research papers on patients affected by ischemic pain.

Recent studies show that SCS has been associated with significant cost-effectiveness rates when compared to the conventional pharmacological pain management (Table 4). Regardless of the initial high cost of SCS, this treatment resulted in significant rates of pain reduction, and a lower cost of conventional therapies after the $1^{\text {st }}$ year of the treatment.

\section{CONCLUSION}

SCS is an initial and a controversial procedure, in which the substantial assessment demonstrated heterogeneous patients and methodologies, implying the high degree of difficulty related to the analysis of results. In this light, Kemler et al. (47) presented that only $56 \%(n=20 / 54)$ of patients with an implanted system were reported at the final 5-year follow-up, despite the high patient satisfaction.

Based on the literature review and authors' experience, recent studies have shown that SCS is an effective adjunctive therapy in patients with medically refractory neuropathic pain. Although the total control of pain with SCS has not been commonly described, this procedure has been associated with significant improvement in the life quality of these patients.

\section{REFERENCES}

1. Schestatsky P. Definition, diagnosis and treatment of neuropathic pain. Rev HCPA 2008;28(3):177-87.

2. Merskey H, Bogduk N. Classification of Chronic Pain. Seattle: IASP Press 1994. 
3. Bennett MI, Smith BH, Torrance N, Lee AJ. Can pain can be more or less neuropathic? Comparison of symptom assessment tools with ratings of certainty by clinicians. Pain 2006;122(3):289-94 .

https://doi.org/10.1016/j.pain.2006.02.002.

4. Galvão AC. Dor Neuropática: Tratamento com Anticonvulsivantes. São Paulo: Segmento Farma; 2005.

5. Treede RD, Jensen TS, Campbell JN, Cruccu G, Dostrovsky JO, Griffin JW, et al. Neuropathic pain: Redefinition and a grading system for clinical and research purposes. Neurology 2007;70(18):1630-5.

https://doi.org/10.1212/01.wnl.0000282763.29778.59.

6. Bouhassira D, Lantéri-Minet M, Attal N, Laurent B, Touboul C. Prevalence of chronic pain with neuropathic characteristics in the general population. Pain 2008;136(3):380-7. https://doi.org/10.1016/j.pain.2007.08.013.

7. Gordon A, Hitchcock ER. IIIness behaviour and personality in intractable facial pain syndromes. Pain 1983;17(3):267-76 https://doi.org/10.1016/0304-3959(83)90099-4.

8. Torrance N, Smith BH, Bennett MI, Lee AJ. The epidemiology of chronic pain of predominantly neuropathic origin. Results from a general population survey. J Pain 2006;7(4):281-9. https://doi.org/10.1016/j. jpain.2005.11.008

9. Dworkin RH, Backonja M, Rowbotham MC, Allen RR, Argoff $C R$, Bennett GJ, et al. Advances in neuropathic pain: Diagnosis, mechanisms, and treatment recommendations. Arch Neurol 2003;60(11):1524-34. https://doi.org/10.1001/archneur.60.11.1524.

10. Attal N, Cruccu G, Haanpaa M, Hansson P, Jensen TS, Nurmikko T, et al. EFNS Task Force. EFNS guidelines on pharmacological treatment of neuropathic pain. Eur J Neurol. 2006;13:1153-69. https://doi.org/10.1111/j.1468-1331.2006.01511.x.

11. Davies HT, Crombie IK, Macrae WA, Rogers KM. Pain clinic patients in Northern Britain. Pain Clin 1992;5:129-35.

12. Grond S, Radbruch L, Meuser T, Sabatowski R, Loick G, Lehmann KA, et al. Assessment and treatment of neuropathic cancer pain following WHO guidelines. Pain 1999;79(1):15-20.

https://doi.org/10.1016/S0304-3959(98)00138-9.

13. Cruccu G, Aziz TZ, Garcia-Larrea L, Hansson P, Jensen TS, Lefaucheur JP, et al. EFNS guidelines on neurostimulation therapy for neuropathic pain. Eur J Neurol 2007;14(9):952-70. https://doi.org/10.1111/j.1468-1331.2007.01916.x.

14. Kim E, Roh M, Kim S, Jo D. Continuous thoracic sympathetic ganglion block in complex regional pain syndrome patients with spinal cord stimulation implantation. Pain Res Manag 2016;2016:5461989. https://doi.org/10.1155/2016/5461989.

15. Kim SH, Tasker RR, Oh MY. Spinal cord stimulation for nonspecific limb pain versus neuropathic pain and spontaneous versus evoked pain. Neurosurgery 2001;48(5):1056-64.

16. Teixeira MJ, Paz MG, Bina MT, Santos SN, Raicher I, Galhardoni R, et al. Neuropathic pain after brachial plexus avulsion central and peripheral mechanisms. BMC Neurol 2015;4(15):73.

https://doi.org/10.1186/s12883-015-0329-x.

17. Teixeira MJ, Paiva WS, Assis MS, Fonoff ET, Bor-Seng-Shu E, Cecon AD, et al. Neuropathic pain in patients with spinal cord injury: Report of 213 patients. Arq Neuropsiquiatr 2013;71(9A):600-3.

https://doi.org/10.1590/0004-282X20130103.

18. Teixeira MJ. Challenges in the treatment of neuropathic pain. Drugs Today (Barc) 2009;45 Suppl C:1-5.

19. Lamé IE, Peters ML, Patijn J, Kessels AG, Geurts J, van Kleef M, et al. Can the outcome of spinal cord stimulation in chronic complex regional pain syndrome Type I patients be predicted by catastrophizing thoughts? Anesth Analg 2009;109(2):592-9. https://doi.org/10.1213/ane.0b013e3181a9082b.

20. Oliveira AS, Gabbai AA. Abordagem terapêutica da dor neuropática. Rev Neuroci 1998;6(2):87-95.

21. Oliveira JO Jr., Corrêa CF, Ferreira JA. Tratamento invasivo para o controle da dor neuropática. Rev Dor 2016;17(1):98-106.

22. Corrêa CF. Estimulação medular nas neuropatias dolorosas. Ambito Hopitalar 2010;200:37-58.

23. Boucher C, Girard M, Drolet P, Grenier Y, Bergeron L, Truong HH Intrathecal Fentanyl does not modify the duration of spinal procaine block. Can J Anesth 2001;48(5):466-9.

https://doi.org/10.1007/BF03028310.

24. Murphy DF, Giles KE. Dorsal column stimulation for pain relief from intractable angina pectoris. Pain 1987;28(3):365-8. https://doi.org/10.1016/0304-3959(87)90070-4

25. Nashold BS, Friedman H. Dorsal column stimulation for control of pain Preliminary report on 30 patients. J Neurosurg 1972;36(5):590-7. https://doi.org/10.3171/jns.1972.36.5.0590.

26. Moura AM, Coubes P. Implante de eletrodo medular epidural. In: Antunes AC, Aguiar PH, Canheu AC, Zicarelli CA, Ramina R, Isolan GR, et al. Principios Técnicos de Neurocirurgia-Atlas e Texto. São Paulo: Dilivro; 2016. p. 57-570.

27. Cameron T. Safety and efficacy of spinal cord stimulation for the treatment of chronic pain: A 20-year literature review. J Neurosurg (Spine). 2004;100 3 Suppl:254-267.

https://doi.org/10.3171/spi.2004.100.3.0254.

28. Jeon $\mathrm{YH}$. Spinal cord stimulation in pain management: A review. Korean $J$ Pain 2012;25(3):43-150.

https://doi.org/10.3344//kjp.2012.25.3.143.

29. Shealy CN, Mortimer JT, Reswick JB. Eletrical inhibition of pain by stimulation of the dorsal columns: preliminary clinical reports. Anesth Analag 1967;46:489-491.

https://doi.org/10.1213/00000539-196707000-00025

30. Meyerson BA, Linderoth B. Mode of action of spinal cord stimulation in neuropathic pain. J Pain Symptom Manage 2006;31(4):6-12.

31. Deogaonkar M, Sharma M, Oluigbo C, Nielson DM, Yang X, Vera-Portocarrero L, et al. Spinal cord stimulation (SCS) and functional magnetic resonance Imaging (fMRI): Modulation of cortical connectivity with therapeutic SCS. Neuromodulation 2016;19(2):142-53.

https://doi.org/10.1111/ner.12346.

32. Kemler MA, Barendse GA, Van-Kleef M, Egbrink MG. Pain relief in complex regional pain syndrome due to spinal cord stimulation does not depend on vasodilation. Anesthesiology 2000;92(6):1653-60.

https://doi.org/10.1097/00000542-200006000-00024.

33. Simpson BA. Spinal cord and brain stimulation. In: Wall PD, Melzack R, editors. Textbook of Pain. $4^{\text {th }}$ ed. London: Churchill Livingstone; 1999. p. 1253-381.

34. Oakley JC, Prager JP. Supplement: Interventional management of chronic benign spinal pain syndromes spinal cord stimulation: Mechanisms of action. Spine 2002;27(22):2574-83. https://doi.org/10.1097/00007632-200211150-00034.

35. Meyerson BA, Linderoth B. Mechanisms of spinal cord stimulation in neuropathic pain. Neurol Res 2000;22(3):285-92. https://doi.org/10.1080/01616412.2000.11740672.

36. Melzack R, Wall PD. Pain mechanisms: A new theory. Science 1965;150:971-9. https://doi.org/10.1126/science.150.3699.971.

37. Moens M, Sunaert S, Mariën P, Brouns R, De Smedt A, Droogmans S, et al. Spinal cord stimulation modulates cerebral function: An fMRI study. Neuroradiology 2012;54(12):1399-407.

https://doi.org/10.1007/s00234-012-1087-8. 
38. Lee AW, Pilitsis JG. Spinal cord stimulation: indications and outcomes. Neurosurg Focus 2006;21(6):E3.

39. Taylor RS, Van-Buyten JP, Buchser E. Spinal cord stimulation for complex regional pain syndrome: A systematic review of the clinical and cost-effectiveness literature and assessment of prognostic factors. Eur J Pain 2006;10(2):91-101.

https://doi.org/10.3171/foc.2006.21.6.6.

40. Taylor RS, Van Buyten JP, Buchser E. Spinal cord stimulation for chronic back and leg pain and failed back surgery syndrome: A systematic review and analysis of prognostic factors. Spine 2005;30(1):152-60.

https://doi.org/10.1097/01.brs.0000149199.68381.fe.

41. Kumar K, North R, Taylor R, Sculpher M, Abeele CV, Gehring M, et al. Spinal cord stimulation versus conventional medical management: A prospective, randomised, controlled, multicentre study of patients with failed back surgery syndrome (PROCESS study). Neuromodulation. 2005;8(4):213-8.

https://doi.org/10.1111/j.1525-1403.2005.00027.x.

42. Sears NC, Machado AG, Nagel SJ, Deogaonkar M, Stanton-Hicks M, Rezai AR, et al. Long-term outcomes of spinal cord stimulation with paddle leads in the treatment of complex regional pain syndrome and failed back surgery syndromener. Neuromodulation 2011;14(4):312-8.

https://doi.org/10.1111/j.1525-1403.2011.00372.x.

43. Simpson BA. Spinal cord stimulation. Pain Rev 1994;1:199-230.

44. Sindou MP, Mertens $P$, Bendavid U, Garcia-Larrea L, Mauguière F. Predictive value of somatosensory evoked potentials for long-lasting pain relief after spinal cord stimulation: Practical use for patient selection. Neurosurgery 2003;52(6):1374-84

https://doi.org/10.1227/01.NEU.0000064570.17828.88.

45. Chincholkar M, Eldabe S, Strachan R, Brookes M, Garner F, Chadwick R, et al. Prospective analysis of the trial period for spinal cord stimulation treatment for chronic pain. Neuromodulation 2011;14(6):523-8. https://doi.org/10.1111/j.1525-1403.2011.00384.x.

46. Kemler MA, Furnée CA. Economic evaluation of spinal cord stimulation for chronic reflex sympathetic dystrophy. Neurology 2002;59(8):1203-9. https://doi.org/10.1212/01.WNL.0000028686.74056.E3.

47. Kemler MA, Vet HC, Barendse GA, Van-Den-Wildenberg FA, Kleef MV. Effect of spinal cord stimulation for chronic complex regional pain syndrome Type I: five-year final follow-up of patients in a randomized controlled trial. J Neurosurg 2008;108:292-8.

https://doi.org/10.3171/JNS/2008/108/2/0292

48. Geurts JW, Smits H, Kemler MA, Brunner F, Kessels AG, van-Kleef M. Spinal Cord stimulation for complex regional pain syndrome Type I: A prospective cohort study with long-term follow-up. Neuromodulation 2013;16(6):523-9.

https://doi.org/10.1111/ner.12024.

49. Kemler MA, Vet HC, Barendse GA. The effect of spinal cord stimulation in patients with chronic reflex sympathetic dystrophy: Two years' follow-up of the randomized controlled trial. Ann Neurol. 2004;55(1):13-8.

https://doi.org/10.1002/ana.10996

50. Olsson GL, Bjorn AM, Linderoth B. Spinal cord stimulation in adolescents with complex regional pain syndrome Type I (CRPS-I). Eur J Pain 2008;12:53-9

https://doi.org/10.1016/j.ejpain.2007.02.007.

51. Mearini M, Podetta S, Catenacci E, d'Auria P, Cornali C, Mortini P. Spinal cord stimulation for the treatment of upper and lower extremity neuropathic pain due to lyme disease. Neuromodulation 2007;10(2):142-7.

https://doi.org/10.1111/j.1525-1403.2007.00102.x.

52. Simpson EL, Duenas A, Holmes MW, Papaioannou D, Chilcott J. Spinal cord stimulation for chronic pain of neuropathic or ischaemic origin: systematic review and economic evaluation. Health Technol Assess

\section{9;13(17):151-4}

https://doi.org/10.3310/hta13170.

53. Turner JA, Loeser JD, Deyo RA, Sanders SB. Spinal cord stimulation for patients with failed back surgery syndrome or complex regional pain syndrome: A systematic review of effectiveness and complications. Pain 2004;108:137-47.

https://doi.org/10.1016/j.pain.2003.12.016.

54. Van-Eijs F, Smits H, Geurts JW, Kessels AG, Kemler MA, Van-Kleef M, et al. B rush-evoked allodynia predicts outcome of spinal cord stimulation in complex regional pain syndrom Type 1. Eur J Pain 2010;14(2):164-9. https://doi.org/10.1016/j.ejpain.2009.10.009.

55. Williams KA, Korto K, Cohen SP. Spinal cord stimulation: Neural switch in complex regional pain syndrome Type I. Pain Med 2009;10:762-6.

https://doi.org/10.1111/j.1526-4637.2009.00630.x.

56. Harke H, Gretenkort P, Ladleif HU, Rahman S. Spinal cord stimulation in sympathetically maintained complex regional pain syndrome Type I with severe disability-a prospective clinical study. Eur J Pain 2005;9:363-373. https://doi.org/10.1016/j.ejpain.2004.09.003.

57. Manca A, Kumar K, Taylor RS, Jacques L, Eldabe S, Meglio M, et al. Quality of life, resource consumption and costs of spinal cord stimulation versus conventional medical management in neuropathic pain patients with failed back surgery syndrome (PROCESS Trial). A. Eur J Pain 2008;12:1047-58. https://doi.org/10.1016/j.ejpain.2008.01.014.

58. Kumar K, Rizvi S, Bnurs SB. Spinal cord stimulation is effective in management of complex regional pain syndrome I: Fact or fiction. Neurosurgery 2011;69:566-580.

https://doi.org/10.1227/NEU.0b013e3182181e60

59. North RB, Kidd DH, Farrokhi F, Piantadosi SA. Spinal cord stimulation versus repeated lumbosacral spine surgery for chronic pain: A randomized, controlled trial. Neurosurgery 2005;56:98-106.

https://doi.org/10.1227/01.NEU.0000144839.65524.E0.

60. Kumar K, Taylor RS, Jacques L, Eldabe S, Meglio M, Molet J, et al. Spinal cord stimulation versus conventional medical management for neuropathic pain: a multicentre randomised controlled trial in patients with failed back surgery syndrome. Pain 2007;132(1-2):179-88.

https://doi.org/10.1016/j.pain.2007.07.028.

61. Wills B, Monsalveb G, Álvarez D, Amaya W, Moyano J, Buitragoc AF. Neuroestimulador espinal para el tratamiento de la angina cardiaca refractaria. Rev Colomb Cardiol 2015;22(6):312-7.

https://doi.org/10.1016/j.rccar.2015.06.011.

62. Vaarwerk IA, Jessurun GA, DeJongste MJ, Andersen A, Mannheimer C, Eliasson T, et al. Clinical outcome of patients treated with spinal cord stimulation for therapeutically refractory angina pectoris. Heart 1999;82:82-8. https://doi.org/10.1136/hrt.82.1.82.

63. Vaidyaraman M, Staats PA. Cancer pain management, anesthesiologic interventions, spinal cord stimulation, and neuraxial infusion. Encyclopedia of Pain. Encyclopedia of Pain: Springer; 2007. p. 233-5.

64. Viswanathan A, Phan PC, Burton AW. Use of spinal cord stimulation in the treatment of phantom limb pain: case series and review of the literature. Pain Pract 2010;10(5):479-84. https://doi.org/10.1111/j.1533-2500.2010.00374.

65. Cioni B, Meglio M, Pentimalli L. Spinal cord stimulation in the treatment of paraplegic pain. J Neurosurg 1995;82(1):35-9.

https://doi.org/10.3171/jns.1995.82.1.0035.

66. Meglio M, Cioni B, Rossi GF. Spinal cord stimulation in management of chronic pain: A 9-year experience. J Neurosurg 1989;70(4):519-24. https://doi.org/10.3171/jns.1989.70.4.0519.

67. Meglio M, Cioni B, Visocchi M, Tancredi A, Pentimalli L. Spinal cord stimulation in low back and leg pain. Stereotact Funct Neurosurg. 1994;62(1-4):263-6. 
https://doi.org/10.1159/000098630.

68. Santos CA, Svartman C, Alirio J, Lianza S. Espasticidade: Procedimentos Cirurgicos Orthopedicos. São Paulo: Associacao Brasileira de Medicina Fisica e Reabilitacao; 2006.

69. Franzini A, Ferroli P, Marras C, Broggi G. Huge epidural hematoma after surgery for spinal cord stimulation. Acta Neurochir (Wien) 2005;147:565-7. https://doi.org/10.1007/s00701-004-0470-6.

70. Hollingworth W, Turner JA, Welton NJ, Comstock BA, Deyo RA. Costs and cost-effectiveness of spinal cord stimulation (SCS) for failed back surgery syndrome an observational study in a workers' compensation population.
SPINE 2011;36(24):2076-83.

https://doi.org/10.1097/BRS.0b013e31822a867c.

71. Dario A, Fortini G, Bertollo D, Bacuzzi A, Grizzetti C, Cuffari S. Treatment of failed back surgery syndrome. Neuromodulation 2001;4:105-10

https://doi.org/10.1046/j.1525-1403.2001.00105.x.

72. Ohnmeiss DD, Rashbaum RF, Bogdanffy GM. Prospective outcome evaluation of spinal cord stimulation in patients with intractable leg pain. Spine 1996;21(11):1344-51.

https://doi.org/10.1097/00007632-199606010-00013 . 